\title{
Reconstituindo memórias e construindo histórias: as relações entre a folia de reis de Florínea (SP) e a história da cidade
}

\author{
Reconstructing memories and building stories: the relationship \\ between the folia de reis from Florinea (São Paulo, Brazil) and the \\ city's history
}

\author{
RAFaela Sales GoularT ${ }^{1}$ \\ Fabiana Lopes da CUnha ${ }^{2}$
}

1 Mestre em história pela Universidade Estadual Paulista, campus de Assis.

E-mail: rafa_historia@hotmail.com

2 Professora doutora na Universidade Estadual Paulista, campus de Ourinhos. É credenciada no programa de pós-graduação em História da Universidade Estadual Paulista, campus de Assis, na linha de pesquisa "Cultura, historiografia e patrimônio". E-mail: fabiana@ourinhos.unesp.br

\begin{abstract}
Parte das reflexões desenvolvidas na pesquisa de mestrado, cujo título é Os sentidos da folia de reis em Florinea/SP: memória, identidade e patrimônio (1993-2013), o texto objetiva reconstituir a história de Florínea, bem como a da região pela qual o grupo de folia de reis (foliões, membros da Associação Folclórica Flor do Vale de Florínea e simpatizantes da folia de reis) estudado constrói sua identidade local. Para isso, serão utilizadas memórias documentais escritas (atas anuais de 1990 a 2012) e orais (21 entrevistas), produzidas entre os anos de 1990 e 2014. A documentação permite a percepção das relações entre a história da folia de reis de Florínea e a história da cidade que se formam entre terras e fazendas limitadas ou não ao atual território de Florínea. Nesse sentido, além das ditas relações, tanto este texto quanto as fontes levantadas durante a pesquisa tornam-se materiais que contribuem para novas investigações e abordagens que dizem respeito à cidade e à folia de reis nela praticada.
\end{abstract}

Palavras-chave: Memória; folia de reis; Florínea (SP).

\begin{abstract}
As a part of the reflections developed during the Master's degree research entitled The meanings of folia de reis in Florinea/SP: memory, identity and patrimony (1993-2013), this text aims at reconstructing the history of Florínea, São Paulo, Brazil, and of the region where the studied group of folia de reis (revelers, members of Flor do Vale Folkloric Association from Florínea and sympathizers of folia de reis) forms its local identity. For this, written (annual minutes from 1990 to 2012) and oral (21 interviews) documentary memories, produced between 1990 and 2014, will be used. The documentation allows the perception of the relations between the history of the Florínea's folia de reis and the history of the city, relations established among lands and farms limited or not by the current territory of Florínea. In this sense, besides the given relations, both this text and the sources listed during the research become materials that contribute to new researches and approaches that concern the city and the folia de reis practiced there.
\end{abstract}

Keywords: Memory; folia de reis; Florínea (SP). 


\section{INTRODUÇÃO}

Este texto é fruto da pesquisa de mestrado desenvolvida no programa de pós-graduação da Universidade Estadual Paulista "Júlio de Mesquita Filho" (UNESP) de Assis, sob a orientação da professora doutora Fabiana Lopes da Cunha. Como o próprio título subentende Os sentidos da folia de reis em Florínea/SP: memória, identidade e patrimônio (1993-2013) -, a pesquisa pretende registrar e analisar a folia de reis a partir das perspectivas do grupo que a realiza na cidade de Florínea (SP) e, dessa forma, colaborar com a preservação de um patrimônio imaterial constantemente ressignificado por meio das vivências daqueles que o praticam. Como indicado, o recorte cronológico da pesquisa é contemporâneo: já no ato de elaboração de seu projeto, averiguou-se a incipiência de documentos relacionados à temática, anteriores à década de 1990. Tal fato, por sua vez, possibilitou elaborar um plano metodológico a partir da história oral.

Nesse pressuposto, Verena Alberti (2010) norteia os passos desta pesquisa - preparação, realização, tratamento e análise da fonte oral -, e ainda auxilia na sua fase final; ou seja, a interpretação daquilo que até então foi produzido. Resumidamente, o preparo das entrevistas delimitou o público com que se trabalha; ou seja, os 21 foliões $^{3}$ de reis distribuídos entre membros do ritual religioso (músicos e palhaços), integrantes da atual Associação de Reis Flor do Vale de Florínea (equipe que organiza a celebração) e simpatizantes da folia de reis (pessoas reconhecidas pelos demais sujeitos do grupo e que, de certa forma, contribuem para a continuidade da celebração). Essa seleção foi elaborada, pois os membros apresentariam os sentidos da festa não só no período atual, mas também trariam consigo um legado de informações, uma vez que essa prática cultural geralmente é compartilhada pelos laços de família que transcendem a ligação sanguínea, principalmente quando se trata de uma cidade com menos de três mil habitantes, como é o caso de Florínea. Essa conclusão, por exemplo, resultou de reflexões sobre relatos de foliões que não tinham uma herança cultural familiar e que, assim, estavam vinculados à folia de reis porque ela os atraiu de alguma maneira, seja no quesito sagrado, lúdico, econômico, político ou mesmo na junção desses vieses.

3 Esse número não representa a soma de todos os integrantes do grupo Flor do Vale. Entretanto, os depoimentos levantados já respondem as questões propostas no trabalho.
Assim, mediante a temática escolhida e os objetivos trilhados, as entrevistas foram desenvolvidas por um roteiro geral que versava sobre as relações entre o entrevistado e a folia de reis de Florínea - os primeiros contatos, o que ouviu falar, como é a folia de reis hoje, como era antes, o que o grupo faz etc - bem como de perguntas mais específicas sortidas durante as entrevistas que, evidentemente, exigem que os indivíduos rememorem acontecimentos que lhes são importantes".

É importante salientar que o contato com os foliões foi importante para o conhecimento de outros documentos, como: o livro de atas que contêm descrições de reuniões anuais realizadas entre 1990-2012; o livro de constituição da recém-formada Associação Folclórica de Reis Flor do Vale de Florínea, oficializando seu nome em 2013 e também suas normas e regras a serem cumpridas pelos membros do grupo; e um caderno com versos, fotografias ilustrativas, músicas gravadas em CDs e DVDs com os momentos da festa que contribuem com a história da folia de reis em Florínea.

Trilhado esse caminho, resta a cuidadosa tarefa de analisar e entrecruzar todas as informações presentes nas documentações. Portanto, neste texto, o objetivo central é a reconstituição da história de Florínea, bem como da região pela qual o grupo de folia de reis (foliões, membros da Associação Folclórica de Reis Flor do Vale de Florínea e simpatizantes da folia de reis) constrói sua identidade local. Essa reconstituição, possível por meio da análise das memórias produzidas, comumente, nos documentos orais (21 entrevistas) e escritos (atas anuais de 1990 a 2012) $)^{5}$, dará ênfase nas relações que foram percebidas a partir de relatos que tendem a relacionar a história de fundação da folia de reis na região de Florínea com a história de fundação da cidade, o que acaba por reforçar a identidade tradicional do grupo.

4 Segundo Alberti (2010), para auxiliar a realização das entrevistas, é importante pensar em toda sua dinâmica, incluindo o local, o aparelho de gravação e o seu posterior armazenamento, o uso de um caderno de campo para anotar algo que posteriormente pode ser esquecido (uma fala não nítida, um momento de emoção), os cuidados com a questão dos direitos autorais, entre outras dicas que auxiliam a difícil tarefa de produzir fontes orais.

5 A análise das documentações leva em consideração o sentido coletivo do grupo, ou seja, quando foram citadas entrevistas específicas de sujeitos que integram a Flor do Vale, elas não contrapõem ideias expressas por outros foliões. 
O texto será desenvolvido em duas partes: a primeira explicará o que é a folia de reis e como ela é praticada em Florínea; na segunda parte, haverá uma reconstituição historiográfica dos sentidos produzidos entre a folia de reis de Florínea e a história da cidade, as quais foram permitidas através da interpretação da percepção social de fatos (THOMPSOM, 2002) vivenciados por aqueles que formam o atual grupo de folia de reis.

Inicialmente, faz-se necessário delinear a área deste estudo. Florínea está localizada na região oeste do estado de São Paulo, fazendo divisa com o estado do Paraná e nos limites de Tarumã, Pedrinhas Paulista e Cândido Mota, todas pertencentes à mesorregião de Assis. Afasta-se de sua capital São Paulo em aproximadamente $487 \mathrm{~km}$. Segundo dados relativos ao censo de 2010 do $\mathrm{IBGE}^{6}$, apresenta uma área territorial de $225.661 \mathrm{~km}^{2}$ e uma população que corresponde a 2.829 habitantes. Foi emancipada em $1953^{7}$, sendo atualmente administrada pelo prefeito Rodrigo Siqueira da Silva e pelo seu vice Aparecido da Silva.

A economia da cidade é baseada na produção agrícola (cana-de-açúcar, arroz, milho, soja, trigo, aveia e banana), pecuária, aquicultura, galináceos, suínos e derivados. A maioria da população empregada de Florínea trabalha em usinas de açúcar e álcool instaladas em Tarumã (empresas Nova América, Raízen e Destilaria Água Bonita), no comércio local e, em menor medida, em cargos públicos ligados à prefeitura e ao Estado.

Com relação à cultura, o censo do IBGE de 2010 apresenta que a maioria da população florinense é católica (2.138 hab.), seguida por evangélicos (567 hab.) e, em sua minoria, por espíritas (9 hab.). Entre as manifestações culturais presentes na cidade ${ }^{8}$, destacam-se a folia de reis (com a festa final no dia 6 de janeiro, dia de Reis), a encomenda das almas (realizada no período da quaresma, é uma procissão noturna em oração e louvor às almas, geralmente é terminada no cruzeiro do cemitério local) e o moçambique (dança de origem africana em

6 Disponível em: <http://bit.ly/2eJ6X74>. Acesso em: 18 dez. 2015.

7 Disponível em: <http://bit.ly/2fzSSIw>. Acesso em: 18 dez. 2015.

8 Informações encontradas no site da Prefeitura Municipal de Florínea. Disponível em: <http://bit.ly/2fzzrll>. Acesso em: 18 dez. 2015. louvor a São Benedito, prática ligada à missa afro 9 , em Florínea) e, por último, a festa junina (realizada nos dias 24 de junho, dia de São João; entretanto, a festa junina também é atribuída a Santo Antônio e São Pedro).

\section{A FOLIA DE REIS DE FloRÍNEA}

Proveniente do catolicismo popular europeu, as folias de reis ${ }^{10}$ vieram para o Brasil com os portugueses e aqui continuaram sendo reelaboradas a partir dos lugares por onde são realizadas e pelos sujeitos que a praticam. São celebradas, geralmente, entre os dias 25 de dezembro (dia de Natal) e 6 de janeiro (dia de Reis ou Epifania), momento em que os componentes da festa (grupo de músicos, palhaços, bandeireiros), junto de seus elementos simbólicos (bandeiras, indumentária), representam a viagem feita pelos magos do oriente em busca do menino Jesus. Na prática cultural, esses foliões visitam casas de devotos e simpatizantes da celebração para rezar, cantar e arrecadar prendas (alimentos, bebidas e dinheiro) que são compartilhadas na festa final do dia 6 de janeiro em uma grande refeição. Dos autores brasileiros que trabalharam com a cultura popular nacional e, dessa maneira, também com a folia de reis, destacam-se os folcloristas Mello Morais Filho (2002), Luís Câmara Cascudo (1999), a dupla Zaíde Maciel de Castro e Aracy do Prado Couto (1977) e o antropólogo Carlos Brandão (1984).

Em Florínea, atualmente, o grupo de folia de reis, o qual chamaremos de Flor do Vale, é subdividido em 2 equipes conhecidas como "bandeiras", "batalhões" ou "companhias". Cada uma delas possui um "mestre", "contramestre", "tala", "contratala", "contrato", "contratinho" e "tipe/rititipe/gritinho/espichado" que, nessa sequência musical, entoam os versos e as músicas que fazem alusão tanto às narrativas bíblicas do Nascimento de Jesus, Adoração dos magos e Fuga para o Egito: Massacre dos Inocentes, episódios encontrados no primeiro capítulo do evangelho de São Mateus (2000), quanto à própria história do grupo,

9 O que difere a tradicional missa católica (celebração da eucaristia) da missa afro são as caracterizações dos participantes e do lugar onde ela é realizada; ou seja, as indumentárias são coloridas e a decoração é feita com frutas e folhas de árvores, expressando o imaginário dos participantes sobre a África.

10 Também conhecidas como "janeiras", "ranchos", "reis", "reisado" e "ternos". Consultar verbetes em Cascudo (1999). 
rememorando nomes de antigos participantes e milagres. Além dos músicos, existe um "capitão/ponteiro", elemento responsável pela organização do grupo durante o giro das bandeiras pela região. Cabe a ele delimitar sua trajetória e os lugares onde serão realizadas as refeições diárias da equipe. O grupo precisa também de um "bandeireiro" para carregar a bandeira ${ }^{11}$, principal instrumento simbólico que é protegido, por sua vez, por 2 ou 3 "palhaços/bastiões" munidos com uma indumentária feita de tecidos de chita e de máscaras que, de acordo com alguns relatos, representam tanto os 3 reis magos (Baltazar, Melquior e Gaspar) quanto os guardas "convertidos" do rei Herodes. Os palhaços, além de dançar e animar o festejo, são responsáveis também por declamar versos diante dos altares/presépios encontrados nas casas, bem como no dia da festa final. E, para fechar a equipe, atualmente, há um "motorista" que leva o grupo, com o ônibus cedido pela prefeitura de Florínea, para os lugares indicados pelo capitão.

Já dentro da equipe que compreende a Associação de Reis Flor do Vale de Florínea, existe o "presidente", o "vice-presidente", o $1^{\circ}$ e $2^{\circ}$ "secretários", o "tesoureiro", o "vice-tesoureiro", 3 membros que compreendem o conselho fiscal e 1 "suplente"12. A associação, por sua vez, foi fundada em 4 de janeiro de 2013, entretanto, desde a década de 1990, foi denominada como "comissão" ou "diretoria", a qual sempre foi responsável pela organização da festa no município. Tal organização remete às reuniões que antecedem as festas, onde são discutidas finanças dos anos anteriores, bem como novas ideias que enriquecerão festas posteriores. É importante destacar que, nas atas anuais consultadas, datadas entre os anos de 1990 e 2012, percebeu-se que todas as decisões tomadas pelo grupo são feitas por votação.

O ritual ${ }^{13}$ da Flor do Vale é iniciado no dia 25 de dezembro, onde as bandeiras de número 1 e 2 saem

11 A bandeira representa a presença dos santos reis e a salvação que pode ser oferecida através da fé e crença neles. Além disso, por meio da bandeira, rememora-se graças alcançadas, lugares e foliões diversos, representando também a identidade do grupo de folia de reis.

12 O $2^{\circ}$ secretário é palhaço na bandeira 2 e o suplente é palhaço na bandeira 1. Os membros do conselho fiscal, por sua vez, compõem a equipe de músicos.

13 Entende-se o ritual como os costumes que se repetem todos os anos pelo grupo de foliões, em especial, as práticas dos músicos e palhaços durante o giro da folia de reis pela região de Florínea. para além da cidade de Florínea, visitando diariamente casas de cidades e de bairros rurais da região. O mapa a seguir indica os "giros" ou "jornadas" de visitações das bandeiras:

Figura 1. Giro da Flor do Vale (círculos vermelhos claro e escuro) e incidência de bandeiras de folias de reis pela região (setas vermelhas, azuis e amarelas).

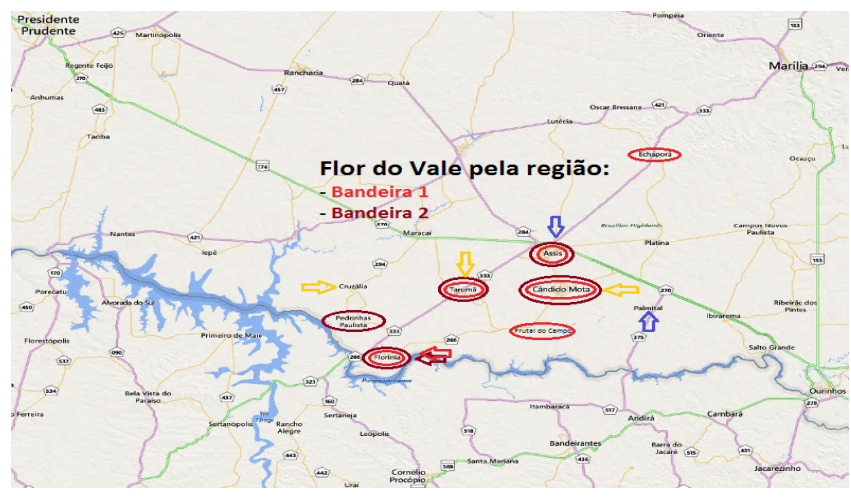

Fonte: Epi info 7.0 do Center of Disease Control (CDC).

Como se percebe no mapa, o grupo Flor do Vale visita além de Florínea, cidades como Pedrinhas Paulista, Tarumã, Cândido Mota (e seu distrito Frutal do Campo), Assis e Echaporã. Além delas, as bandeiras percorrem alguns dos bairros rurais formados por sítios e fazendas que, geralmente, estão próximos de córregos ou microbacias hidrográficas (águas).

De acordo com depoimentos do mestre Fião ${ }^{14}$, sua bandeira (número 1) passa por Água Preta, Água do Barbado, Água do Dourado, Água Suja, Água das Flores, Bugio, Água da Paca, Água da Aldeia, Barreirinho, Quebra Canôa, as quais são pertencentes aos municípios de Florínea e Tarumã. Ele diz também que costuma visitar casas que pertencem a Cândido Mota, situadas em Água do Almoço, Queixadas, São Benedito, Água do Frutal, Barro Preto, Taquaruçuzinho, Taquaruçu e Água das Pedras. Já em relação à bandeira 2 da Flor do Vale, cujo mestre é Benedito de Oliveira Silva ${ }^{15}$ (o mestre Dito), sua

14 Entrevista realizada no dia 22 de julho de 2013, na residência do senhor Benedito da Silva, localizada em Florínea. Com 65 anos de idade, ele acompanha a Companhia Flor do Vale há 59 anos, sendo atualmente o mestre de uma de suas bandeiras. (SILVA, B., 2013).

15 Benedito de Oliveira Silva, o mestre Dito, tem 66 anos de idade. Nasceu em Tarumã, mas atualmente mora em Assis, onde exerce a profissão de pedreiro. Seu primeiro 
bandeira costuma visitar também algumas casas das cidades de Florínea, Tarumã, Cândido Mota, Assis e Pedrinhas Paulista e, além delas, casas pertencentes a sítios de Santo Antônio e da Água Bonita (Tarumã).

Nas entrevistas feitas com o grupo Flor do Vale, averiguou-se a incidência de outras bandeiras ou festas de folia de reis pela região que eles percorrem (setas FIGURA 1). Nesse sentido, identificou-se a presença de bandeiras e festas que ocorrem em Cruzália/Água da Pintada (1), Cândido Mota (1), Tarumã ${ }^{16}$ (1), Assis (1) e, além da região por eles percorrida, citaram a presença de uma bandeira em Palmital, lugar que também possui uma grande festa de reis. Entretanto, as bandeiras supracitadas não percorrem cidades vizinhas como fazem os integrantes da Flor do Vale e, das festas que realizam, nenhuma delas é comemorada no mesmo dia da festa de Florínea. Sobre isso, alguns dos foliões acreditam que seja uma maneira de não haver concorrência entre as festas, reconfigurando assim, o calendário cristão de comemoração aos santos reis pela região.

Posteriormente a esse giro, as bandeiras da Flor do Vale se encontram no dia 6 de janeiro, dia da festa de confraternização daquilo que foi arrecadado. Aliás, já no dia 5, os foliões findam seu giro pela região para ajudar no preparo dos alimentos e na organização do lugar onde a festa é feita em Florínea, ou seja, no Parque de Tradições, Exposições, Leilões e Festejos Prefeito Sebastião Benedito de Paula. O local, embora seja da prefeitura e, portanto, sendo nele possibilitado à realização de qualquer outro evento cultural, é sede da Associação Folclórica de Reis Flor do Vale de Florínea. Dessa forma, de acordo com algumas atas estudadas, muito do que nele tem, como é o caso da capela, dos móveis e vasilhames da cozinha,

contato com a folia de reis se deve ao seu pai, Nicanor de Oliveira Silva e ao seu tio, o embaixador Demervil Martins (Mestre Vila). (SILVA, B. O., 2013).

16 De acordo com Amado Jesus da Silva, a bandeira de folia de reis de Tarumã, atualmente, são pagas pela prefeitura local para cumprirem tal função. Isso mostra que a bandeira também sofreu ressignificações. Amado, por sua vez, tem 82 anos e participa da folia de reis de Florínea há 53 anos, tendo iniciado sua prática na bandeira como contratala. Ele diz que sua ligação com a festa é estritamente familiar, pois seu pai foi o primeiro palhaço na companhia, em 1928, sendo sua mãe (Maria Baślio da Silva) e a mãe do Rozimbo do Nascimento (presidente da Associação de Reis Flor do Vale de Florínea), as primeiras cozinheiras da festa. E já seu irmão, Othon da Silva, foi cantador da folia de reis. (SILVA, A., 2013). jardinagem e outros elementos decorativos, foram adquiridos através da comissão de folia de reis.

O dia de Reis é também feriado na cidade de Florínea (FLORÍNEA, 2009), sendo que a prefeitura libera seus funcionários já com a intenção de que eles ajudem na festança. Aliás, os funcionários públicos da prefeitura que são membros das bandeiras de reis são dispensados também para o giro pela região, o que demonstra a ligação do poder público com essa manifestação cultural.

A festa do dia 6 de janeiro, portanto, é iniciada às 9 horas da manhã com uma missa rezada na capela do Parque de Tradições, onde desde já são entregues para a população presente pão com carne moída; posterior à reza, há o almoço (macarrão, tutu de feijão, churrasco de carne bovina, porco e frango fritos, carne cozida com batata). Às 14 horas, é o momento em que as duas bandeiras da folia de reis chegam ao Parque de Tradições, seguindo cada uma sua direção até a gruta onde os festeiros do ano os esperam junto da imagem da sagrada família - Maria, José e Jesus. Quando se encontram, muitos versos e orações são feitas, pois este é o momento principal da festa, isto é, quando os magos do oriente encontram o menino Jesus. Findado o ritual religioso, há um novo banquete, e, no barracão onde é servido, também são anunciados os novos festeiros do ano posterior ${ }^{17}$.

Por fim, a festa continua no Parque de Tradições que, nesse dia, apresenta muitas barracas ${ }^{18}$ com variados alimentos, bebidas e lembrancinhas que complementam o dia de socialização que se popularizou no município de Florínea.

17 De acordo com os membros da Associação, as pessoas que apresentam interesses na função devem procurar o grupo e, eles por sua vez, anotam os nomes dos interessados em uma lista de espera, a qual é seguida pela ordem. Além disso, atualmente, os festeiros só tem a função de providenciar a indumentária dos palhaços.

18 Tanto nas atas quanto nos depoimentos tivemos informações que, para venderem seus produtos no Parque de Tradições, os comerciantes das barracas precisam pagar um valor para a Associação Folclórica de Reis Flor do Vale de Florínea. O dinheiro arrecadado, por sua vez, é empreendido nela. 


\section{As RELAÇÕES ENTRE A FOLIA DE REIS DE FlorínEA E A HISTÓRIA DA CIDADE}

Os atuais percursos da Flor do Vale (FIGURA 1) apontam para uma ideia de região que se construiu a partir dos laços de identificação da manifestação popular pelos foliões ${ }^{19}$. Ao avaliar a memória do grupo (depoimentos orais e as atas anuais manuscritas a partir da década de 1990), nota-se uma relação entre a história de fundação da cidade e a folia de reis de Florínea, a qual foi desenvolvida a partir da imagem do festeiro Sebastião Alves de Oliveira ${ }^{20}$.

Sobre as primeiras relações constatadas em ambas "as fundações", Rozimbo do Nascimento ${ }^{21}$ diz que a festa teria sido iniciada na região no final da década de $1920^{22}$, em razão de uma promessa feita por Sebastião Alves de Oliveira, o qual estava endividado. Em suas

19 É válido ressaltar que os foliões não são apenas os membros do grupo Flor do Vale, mas também as pessoas significativas para a história do grupo, em outras palavras, são seus simpatizantes, aqueles que esperam as bandeiras e que ajudaram a demarcar seus passos pela região, acolhendo-os e acompanhando-os.

20 Filho de José Alves de Oliveira e Verissima de Oliveira e natural de Ribeirão Preto (SP), Sebastião Alves de Oliveira era casado com Maria José Alves, com quem teve 8 filhos: Lourdes Alves de Oliveira Nicoli, Lair Alves Lanzoni, Helena Alves de Souza, Jorge Alves de Oliveira, Antonio Alves de Oliveira, Paulo Alves de Oliveira, Izabel Alves de Oliveira, Maria de Jesus Alves Ferraz e Benedita Alves da Costa. A última, falecida, deixou a filha Lygia Alves da Costa Miranda Cortes. Sebastião faleceu em 3 de junho de 1951, com 73 anos de idade, sendo enterrado no Cemitério da Saudade em Campinas. Lugar onde, mais tarde, seria enterrada sua mulher. (FLORÍNEA, 1951).

21 Entrevista realizada na residência de Rozimbo do Nascimento, no dia 14 de agosto de 2012, em Florínea (SP). Nascido em 1930 (85 anos), é o atual presidente da Associação de Folclórica de Reis Flor do Vale de Florínea, onde é considerado um de seus pioneiros e, portanto, é pessoa muito respeitada em tal. Ressalta-se que nesta entrevista estava presente o simpatizante da bandeira de reis de Florínea, Onofre Lopes de Lima (morador de Tarumã), e, ao final da entrevista, a esposa de Rozimbo. (NASCIMENTO, 2012).

22 Tendo como pressuposto que as memórias são (re)produzidas oralmente, naturalmente, tanto no depoimento de Nascimento (2012) quanto nos demais relatos fornecidos pelos integrantes do grupo, as datas de realização das primeiras festas de reis oscilaram. Foram apresentados os anos de 1919, 1926 (Livro de atas Santos Reis Florínea. Manuscritos com autorias diversas e datados de 19902011), 1928, 1929, 1932, 1933 e até 1950. palavras: “[...] era 28, 29, por aí. Depois ele (Sebastião) foi vendendo aqui, só ficou com mil alqueires de terra. Mas, teve que vender tudo pra pagar as dívidas". De acordo com Rozimbo, seu pai foi funcionário de Sebastião Alves de Oliveira por pouco mais de 30 anos na Água do Almoço, atual Cândido Mota. Nesse lugar, Sebastião trabalhava em uma serraria junto de "Machado Basto", sendo o primeiro responsável por retirar madeiras da região e o segundo parecia administrar e a comercializar o que era levantado e produzido.

Da Água do Almoço, transferiram-se para o Guaritá, depois para Itaguara do Sul (Taquaruçuzinho/ Frutal do Campo), foram então para a cabeceira da Paca e, por fim, instalaram-se em Barbado, onde Sebastião continuava sua retirada de madeiras. Na fala de Rozimbo, aparentemente Sebastião e "Machado Bastos" disputavam terras, pois afirma que quando Sebastião conquistava um lugar, já colocava gente pra trabalhar, estabelecendo seu território. Entretanto, a situação foi cessada com um acordo em que Sebastião ficava com o Guaritá e Água do Almoço e "Machado Basto" com Itaguara do Sul, Paca e a serraria.

Nesse momento, Rozimbo afirma que Sebastião estava devendo dinheiro pela região, o que resultou em uma promessa aos santos reis. Dessa forma, com um dos seus carreiros, "João/Zé Ignácio ou Zé Orácio"”23, realizaram as folias de reis pela região dos Queixadas (também pertencente a atual Cândido Mota) e, posteriormente, pelas diferentes fazendas e cidades da região, através da herança cultural que, no caso, é associada a uma herança familiar transmitida de pai para filho. No caso, de Sebastião Alves de Oliveira para Jorge Alves de Oliveira.

Por meio dos sinais apresentados nos relatos de Rozimbo do Nascimento, encontrou-se no arquivo do Fórum de Assis, dois processos que ligam Sebastião Alves de Oliveira com o nome "Machado Bastos \& Cia", a qual era uma firma comercial do Rio de Janeiro ${ }^{24}$. Além de comercializar materiais de construção, de decoração e mobiliário, na condição de serraria, Machado Bastos \& Cia trabalhava com a importação de madeiras nacionais e estrangeiras (BRASIL, 1929). Logo, já na data de estabelecimento

23 Rozimbo confunde os nomes, mas, de acordo com a redação do livro de atas, o carreiro se chamava João Ignácio da Silva.

24 Sediada na praia de São Cristóvão, no 39 e representada pelo sócio Avelino Pacheco Machado Bastos. 
do município de Cândido Mota, em 1923, a extração de madeiras era uma atividade comum, sendo que pertenciam à sua indústria madeireira três principais serrarias: Estrada de Ferro Sorocabana, Machado Bastos \& Cia e Serraria Lapa Ltda. (BRASIL, 1948).

Resumindo os processos oficiais encontrados, ambos da década de 1930, o primeiro (FLORÍNEA, 1933) remete ao pedido de destituição de bens do cargo de depositário a Sebastião e, já o segundo (FLORÍNEA, 1937), "Protesto e Contra-Protesto", é uma espécie de conclusão do primeiro, tendo o requerente Sebastião Alves de Oliveira e sua mulher, Maria José de Oliveira, que pagar a Machado Bastos \& Cia uma quantia alta de infrações ocasionadas nos bens hipotecados à credora. Dessa maneira, o segundo processo mostra que Sebastião teve que vender algumas de suas propriedades, como foi o caso da Fazenda Taquarussu e da Água da Paca e suas respectivas benfeitorias, assim findaria tal processo em um acordo entre ambas as partes.

Portanto, a memória da foliona Rozimbo está relacionada à versão oficial dos fatos, atrelando Sebastião Alves de Oliveira e "Machado Basto" ou Machado Bastos \& Cia. E mesmo que tanto o depoimento de Rozimbo quanto os processos levantados contenham nebulosamente os conflitos, ambos são importantes porque mostram um pouco do cenário por onde a memória e a história da folia de reis foram desenvolvidas.

Nos processos foram confirmados bens ligados a Sebastião, como imóveis situados no "Ribeirão dos Queixadas - Taquarussuzão ou Guaritá, Dourado, Adeia, Ribeirão dos Queixadas - Quebra Canôa, Pau Barbado (Água do Pau Barbado), Pau Barbado (Água das Flores ou Água do Pântano) e Água do Almoço" (FLORÍNEA, 1937). Entretanto, com relação à serraria de Cândido Mota, ligada a Machado Bastos \& Cia, não se sabe se ela teve alguma relação com uma serraria localizada no território de Florínea, mencionada no trabalho de Adão Nunes (1993), em que este afirma ter sido extinta uma serraria de Florínea, na década de 1940, por não haver mais reservas de matas para extração de madeiras (NUNES, 1993).

Além dos relatos de Rozimbo, a imagem de Sebastião Alves de Oliveira se torna preponderante tanto no tocante à sua prática de trabalho no lugar que se une à posse de território quanto às benfeitorias feitas por ele, seja nas doações de terras ou na iniciativa de ter trazido a bandeira dos santos reis para o lugar.
Posteriormente à morte do Sebastião em 1951 e de sua esposa em 1953, constam como bens inventariados para os herdeiros: um terreno com uma casa na vila de Florínea, na época município de Assis; uma gleba de terras situadas nas Fazendas Anhuminhas e Pau Barbado, anexadas também à Florínea (1.220 hectares), com fazendas benfeitorias como pés de café (queimados com a geada de 1940), uma casa de morada e seis casas pequenas, um rancho, uma tulha, uma garagem e um depósito; algumas datas vendidas e não vendidas de loteamentos de Florínea; um terreno doado ao grupo escolar do distrito de Florínea; depósitos em dinheiro em três bancos distintos (FLORÍNEA, 1951).

Entretanto, após o falecimento de Sebastião, alguns relatos de foliões mostram o surgimento da aliança entre as duas bandeiras hoje presentes em Florínea, sendo que antes da década de 1960 uma era proveniente do bairro da Paca (bandeira 1) e a outra do Santo Antônio (bandeira 2). De acordo o tesoureiro Alexandre Fabiano Neto (2014), foi nesse período que as bandeiras se uniram e a cidade de Florínea passou a dominá-las. Alexandre ainda mostra que a bandeira que remonta ao ano de 1928 pertencia à $\mathrm{Paca}^{25}$.

Como se percebe, mesmo que exista na memória dos florinenses uma ligação entre a história da folia de reis com a história da cidade, sendo ambas iniciadas na década de 1920, é importante mostrar outras informações contidas em relatos obtidos através das entrevistas orais.

A primeira dessas informações é que a festa, antes celebrada anualmente na casa de festeiros - distintos proprietários de terras e fazendeiros da região -, passa por um momento de crise em algum momento da década de 1980, dada pelo fato do fazendeiro Jorge Alves de Oliveira (filho de Sebastião), de última hora, não ter cedido sua fazenda para realizar a festa. Dessa forma, ao relatar esse episódio, Amado da Silva (2013) rememora os nomes de "Nézião" (Onésimo Gomes de Moraes), Santino Fabiano dos Santos e Alfeu do Nascimento, sendo que o último teria cedido seu sítio para a festa. Assim, depois da situação relatada como uma atitude de salvaguarda da folia de reis, as festas começaram a ocorrer no barracão

25 Alexandre Fabiano Neto tem 42 anos, é natural de Florínea, onde é trabalhador rural. Entrou na folia de reis por influência do seu tio, Santino Fabiano, e hoje é o atual tesoureiro da Associação folclórica de reis Flor do Vale de Florínea. (FABIANO NETO, 2014). 
pertencente ao senhor Ico Caetano ${ }^{26}$, lugar comprado pela prefeitura em 1989 (FLORÍNEA, 1989) para reforma e efetivação do espaço como Parque de Tradições da cidade de Florínea (SILVA, A., 2013).

Complementando a história, nesse período do final de 1980 e início da década de 1990, o grupo de folia de reis se fortalece por meio da organização da comissão/diretoria. Essas impressões são registradas em atas das reuniões anuais, onde são discutidos os assuntos que competem toda dinâmica da festa, incluindo suas possibilidades e dificuldades do cotidiano da cidade de Florínea e dos demais lugares por eles visitados. O sucesso da organização, por sua vez, é confirmado com a criação da Associação de Fonclórica de Reis Flor do Vale de Florínea, em 2013.

\section{CONSIDERAÇÕES FINAIS}

Entre memórias e histórias, a permanência da folia de reis em Florínea passa a ser ressignificada no cenário da cidade. A mudança é implementada com o grupo Flor do Vale que, juntamente do poder público local e dos demais cidadãos florinenses, compartilham a busca pelo reconhecimento de sua identidade por um patrimônio imaterial. Portanto, o texto mostra que a memória coletiva que relaciona a fundação da folia de reis de Florínea com a história da cidade tende a enaltecer a ideia de pertença da festa no lugar, mesmo que a união das bandeiras e própria realização da festa no lugar sejam posteriores ao período rememorado - início do século XX.

Nesse sentido, as perspectivas coletivas analisadas no texto e o seu esclarecimento via entrecruzamentos de fontes colaboram com a salvaguarda da história desse patrimônio florinense que, efetivamente, é documentado a partir da década de 1990.

\section{REFERENNCIAS}

ALBERTI, V. Fontes orais - histórias dentro da história. In: PINSKY, G. B. (Org.). Fontes históricas. São Paulo: Contexto, 2010.

26 Simpatizante da festa e cunhado de Rozimbo do Nascimento (SILVA, A., 2013).
ARCANJO FILHO, J. Entrevista [5 dez. 2013]. Entrevistadora: R. S. Goulart. Florínea, 2013. Áudio MP3 (50 min).

ASSEMBLEIA DE CONSTITUIÇÃO DA ASSOCIAÇÃO FOLCLÓRICA DE REIS FLOR DO VALE DE FLORÍNEA, 2012, Florínea. Ata. Florínea: Associação Folclórica de Reis Flor do Vale de Florínea, 2013.

BRANDÃO, G. R. O que é folclore. São Paulo: Brasiliense, 1984.

BRASIL. Annuario commercial, industrial, agricola, profissional e administrativo da Capital Federal e dos Estados Unidos do Brasil. Rio de Janeiro: Almanak Laemmert, 1929. v. 2. Disponível em: <http://bit.ly/2fXrtTo>. Acesso em: 18 dez. 2015.

Câmara dos Deputados. Projeto de Lei n ${ }^{\circ}$ 891A/1948. Cria, no município de Cândido Mota, no estado de São Paulo, uma coletoria para a arrecadação das rendas federais. Imprensa Nacional, Rio de Janeiro, 1948. 2p. Disponível em: <http://bit.ly/2fBjCH8>. Acesso em: 18 dez. 2015.

GASGUDO, L. G. Dicionário do folclore brasileiro. 10. ed., Rio de Janeiro: Ediouro, 1999.

CASTRO, Z. M.; COUTO, A. P. Folias de Reis. In: FUNDAÇÃO GULTURAL CASSIANO RICARDO; GENTRO DE ESTUDOS DA GULTURA POPULAR. (Ed.). Cadernos de folclore. Rio de Janeiro: Ministério da Educação e Cultura. Departamento de Assuntos Culturais. Fundação Nacional de Arte. Campanha de Defesa do Folclore Brasileiro, 1977.

ELEUTÉrio, D. L. Entrevista [5 dez. 2013]. Entrevistadora: R. S. Goulart. Tarumã, 2013. Áudio MP3 (1 h).

FABIANO NETO, A. Entrevista [30 jun. 2014]. Entrevistadora: R. S. Goulart. Florínea, 2014. Áudio MP3 (1 h 27 min). 
FERREIRA, A. C. Entrevista [30 nov. 2013]. Entrevistadora: R. S. Goulart. Florínea, 2013. Áudio MP3 (1 h).

FLORÍNEA. Instrumento de Agravo (16/10/1933). Processo n ${ }^{\circ}$ 66/33. Arquivo do Fórum de Assis. Florínea: CEDAP/Assis, 1933.

\section{Protesto e Contra-Protesto}

(04/03/1937). Processo $n^{\circ}$ 26/1937. Arquivo do Fórum de Assis. Florínea: CEDAP/Assis, 1937.

Inventário $(28 / 06 / 1951)$. Processo $n^{\circ}$ 199/1951. Arquivo do Fórum de Assis. Florínea: CEDAP/Assis, 1951.

Lei Ordinária no 006/89, de 2 de março de 1989. Autoriza a prefeitura municipal de Florínea a adquirir terreno. Florínea: Prefeitura Municipal de Florínea, 1989.

Lei $n^{\circ}$ 351/2009, de 2 de dezembro de 2009. Dispõe sobre feriados religiosos no município. Florínea: Prefeitura Municipal de Florínea, 2009.

LIMA, O. L. Entrevista [20 abr. 2013]. Entrevistadora: R. S. Goulart. Tarumã, 2013. Áudio MP3 (1 h).

MEIRA FILHO, A. V. Entrevista [7 dez. 2013]. Entrevistadora: R. S. Goulart. Florínea, 2013. Áudio MP3 (24 min).

MORAIS FILHO, M. Festas e tradições populares do Brasil. Brasília: Senado Federal/Conselho Editorial, 2002.

NASGIMENTO, R. Entrevista [14 ago. 2012]. Entrevistadora: R. S. Goulart. Florínea, 2012. Áudio MP3 (1 h).
NUNES, A. G. F. Processo de (des)ocupação de Florínea-SP. 1993. Monografia de Conclusão de Curso (Bacharelado em Geografia) - Universidade Estadual de Londrina, Londrina, 1993.

O EVANGELHO segundo São Mateus. Capítulo 1. In: Bíblia Sagrada - Edição Pastoral Gatequética. 137. ed. rev. Frei João Pedreira de Castro et al. São Paulo: Ave Maria; Glaretiana, 2000, p. 1285-1286.

OLIVEIRA, G. A. Entrevista [7 dez. 2013]. Entrevistadora: R. S. Goulart. Florínea, 2013. Áudio MP3 (53 min).

OLIVEIRA, J. A. Entrevista [5 dez. 2013]. Entrevistadora: R. S. Goulart. Florínea, 2013. Áudio MP3 (1 h 24 min).

OLIVEIRA, J. Florínea. In: FERREIRA, J. P. Enciclopédia dos municípios brasileiros. Rio de Janeiro: IBGE, 1957. v. 28.

SANTOS, A. F. Entrevista [1 nov. 2013]. Entrevistadora: R. S. Goulart. Florínea, 2013. Áudio MP3 (57 min).

SILVA, A. J. Entrevista [15 mai. 2013]. Entrevistadora: R. S. Goulart. Florínea, 2013. Áudio MP3 (1 h 50 min).

SILVA, B. Entrevista [22 jul. 2013]. Entrevistadora: R. S. Goulart. Florínea, 2013. Áudio MP3 (1 h 35 min).

SILVA, B. O. Entrevista [6 dez. 2013]. Entrevistadora: R. S. Goulart. Tarumã, 2013. Áudio MP3 (45 min).

THOMPSON, P. A voz do passado. Rio de Janeiro: Paz e Terra, 2002.

VALIM, J. R. Entrevista $\left[\begin{array}{lll}7 & \text { dez. 2013]. }\end{array}\right.$ Entrevistadora: R. S. Goulart. Florínea/SP, 2013. Áudio MP3 (4 min). 